\title{
Portal Vein Thrombosis and Thrombocytopenia in Eosinophilic Granulomatosis with Polyangiitis: A Paradox?
}

\author{
Frieda Wolf $^{1}$, Karina Glick ${ }^{1}$, Mazen Elias ${ }^{1}$, Reuven Mader $^{2}$ \\ ${ }^{1}$ Department of Internal Medicine C, Emek Medical Center, Itzhak Rabin Blvd., Afula, Israel \\ ${ }^{2}$ Division of Rheumatology, Emek Medical Center, Itzhak Rabin Blvd., Afula, Israel
}

Received: 04/10/2018

Accepted: $15 / 10 / 2018$

Published: 02/11/2018

\begin{abstract}
How to cite this article: Wolf F, Glick K, Elias M, Mader R. Portal vein thrombosis and thrombocytopenia in eosinophilic granulomatosis with polyangiitis: a
\end{abstract} paradox? EJCRIM 2018;5: doi:10.12890/2018_000971.

Conflicts of Interests: The Authors declare that there are no competing interests.

This article is licensed under a Commons Attribution Non-Commercial 4.0 License

\section{ABSTRACT}

A 36-year-old woman with eosinophilic granulomatosis with polyangiitis (EGPA) presented with necrotic skin lesions and pulmonary infiltrates. There was eosinophilic vasculitis on skin biopsy, and substantial tissue eosinophilia in her bone marrow. She had unexplained worsening thrombocytopenia, which prompted a thrombophilia work-up. However, abnormalities in liver enzymes led to the extraordinary finding of portal vein thrombosis. Thrombocytopenia resolved with treatment with low molecular weight heparin. This case highlights the risk of hypercoagulability in eosinophilia specifically, and in EGPA. We suggest that thrombosis should be ruled out in all cases of EGPA.

\section{LEARNING POINTS}

- Eosinophilia is a hypercoagulable state.

- Thrombocytopenia is not part of eosinophilic granulomatosis with polyangiitis (EGPA) and may herald thrombosis.

- Thromboembolism should be ruled out in the setting of EGPA with eosinophilia.

- Prompt diagnosis can prevent unnecessary procedures.

\section{KEYWORDS}

Portal vein thrombosis, hypercoagulability, eosinophilia, EGPA

\section{CASE STUDY}

A 36-year-old non-smoker presented with skin lesions on her abdomen and legs. She was a director of a non-profit organization. She had also had three normal pregnancies and deliveries. In recent months, she had been treated by a dermatologist for a recurrent pruritic urticarial rash. She denied a family history of autoimmune diseases. A week before admission, pruritic, painful lesions appeared on her legs, resembling insect bites. They then seemed to expand, necrotic centres appeared, and the lesions spread to her abdomen. She had no fever, weight loss, headache, nasal discharge, arthralgia, conjunctivitis or morning stiffness.

On admission, $\mathrm{O}_{2}$ saturation was $99 \%$ on room air, blood pressure was $113 / 79 \mathrm{mmHg}$ and temperature $37.4^{\circ} \mathrm{C}$. Examination of the eyes and mouth was normal. There was full range of motion of joints with no swelling. Multiple skin lesions 2-3 cm in diameter covered her lower abdomen and back (Fig. 1) and her lower extremities. Some had a necrotic centre (Fig. 2). Mild crepitations were heard over the right middle lobe. The remainder of her exam was unremarkable. 


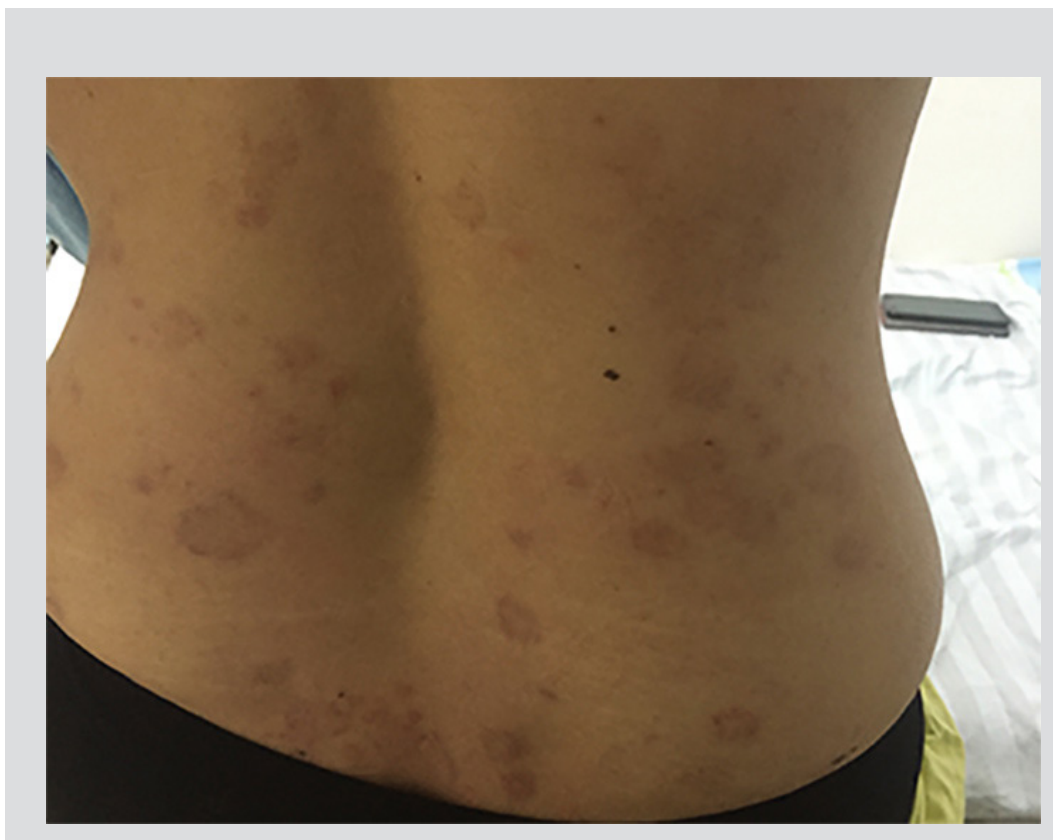

Figure 1. Rash on the patient's back

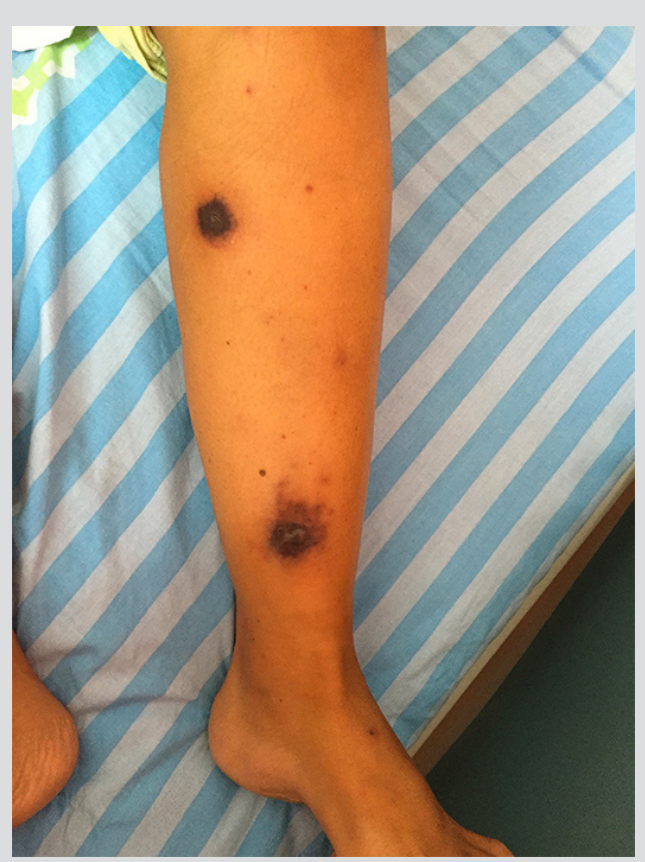

Figure 2. Necrotic lesions on the patient's leg

Complete blood count showed no anaemia, leukocytosis or eosinophilia. Chemistry and creatine phosphokinase were normal. DsDNA was $51 \mathrm{IU} / \mathrm{ml}(<5 \mathrm{IU} / \mathrm{ml})$ and RNP was $2.4 \mathrm{IU} / \mathrm{ml}(<0.8 \mathrm{IU} / \mathrm{ml})$; ANA titre, complement levels and C1 esterase inhibitor were normal. Serologies for $\mathrm{HIV}$, hepatitis B and C were negative. Urinalysis and stool examination were negative. Chest $\mathrm{x}$-ray showed bilateral infiltrates in the middle and lower lobes, more prominent on the right.

Skin allergy testing indicated sensitivity to dust mite. Skin biopsies were taken.

Further work-up included ANCA by immunofluorescence, cryoglobulins, rheumatoid factor, anticardiolipin and lupus anticoagulant, all of which were within normal limits. C-reactive protein was $50 \mathrm{mg} / \mathrm{l}(<5 \mathrm{mg} / \mathrm{l})$ and erythrocyte sedimentation rate was $11 \mathrm{~mm}$.

Prednisolone $40 \mathrm{mg}$ per day was started for suspected vasculitis, while biopsy results were awaited.

On the third hospital day, the patient developed shortness of breath with a fever of $38.2^{\circ} \mathrm{C}$. Oxygen saturation dropped to $93 \%$. D-dimer was $>10,000 \mathrm{ng} / \mathrm{ml}$, with normal PT, PTT. Blood count showed $9.07 \mathrm{~K} / \mu \mathrm{l} \mathrm{WBCs}, 1.05 \mathrm{~K} / \mu \mathrm{l}$ eosinophils (11\% of the total leukocyte count)

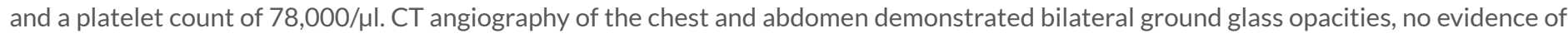
pulmonary embolism, and no involvement of the renal, mesenteric or hepatic arteries. Echocardiogram was normal.

Subsequently, prednisolone was increased to $60 \mathrm{mg}$, and ceftriaxone and azithromycin were added. There was prompt improvement of respiratory symptoms with defervescence. There was also radiographic improvement on chest x-ray. Initial skin biopsy findings showed eosinophilic panniculitis in one lesion, and eosinophilic vasculitis without granulomas in another. This was consistent with eosinophilic granulomatosis with polyangiitis (EGPA). Antibiotics were stopped.

Despite clinical improvement, platelets dropped to 35,000/ul, with elevated D-dimer and low fibrinogen. Doppler examination of the legs ruled out deep vein thrombosis (DVT). We proceeded to bone marrow biopsy, which ruled out marrow failure and revealed mild hyperplasia of megakaryocytes with normal morphology. There was massive infiltration of mature eosinophils, without granulomas, and no evidence of malignancy.

On reviewing the skin biopsies, micro thrombi were found, so prophylactic anticoagulation with low molecular weight heparin (LMWH) was initiated. A persistent rise in AST (60 U/I) and ALT (170 U/I), along with new right upper quadrant tenderness, prompted sonography of the portal and suprahepatic veins, revealing portal vein thrombosis. The dose of LMWH was increased. A whole body positron-emission tomography scan and thrombophilia work-up were normal.

Subsequently, there was consistent improvement of most skin lesions. Thrombocyte count also improved. The patient was discharged with steroid treatment. During follow-up, ALT, AST and platelets normalized. The patient later developed weakness of the right leg, and electromyography confirmed mononeuritis multiplex. 


\section{DISCUSSION}

EGPA is a syndrome affecting small and medium size vessels. It typically involves the lungs and upper respiratory tract, sometimes with glomerulonephritis. The annual incidence has been estimated to be 1-3 per million. A prodrome typically begins with asthma, rhinitis or rash, followed by eosinophilic infiltration of organs. The American College of Rheumatology requires four of the six following criteria for diagnosis ${ }^{[1]}$ :
1. Asthma
2. Greater than $10 \%$ eosinophils on the differential leukocyte count
3. Mononeuropathy (including multiplex) or polyneuropathy
4. Migratory or transient pulmonary opacities detected radiographically
5. Paranasal sinus abnormality
6. Biopsy containing a blood vessel showing the accumulation of eosinophils in extravascular areas.

Our patient presented with a rash followed by necrotic skin lesions and pulmonary infiltrates. There was no evidence of renal or upper respiratory involvement. Urticaria may have been her initial allergic manifestation. Oddly, eosinophilia was virtually absent. Eosinophils, however, were abundant in the bone marrow and around skin vessels. Our patient unequivocally fulfilled the criteria for EGPA: rash, pulmonary opacities, eosinophilic vasculitis and mononeuritis multiplex.

Venous thromboembolism (VTE) has been described in vasculitides, with an incidence of $8 \%$. A large study of 232 patients with EGPA, granulomatosis with polyangiitis and microscopic polyangiitis, found $21 \%$ had pulmonary embolism, $62 \%$ had DVT and $16 \%$ had both ${ }^{[2]}$. In a case series of patients with EGPA, 3.1-18.7\% had arterial thrombosis, and 5.8-30\% venous thrombosis. Ischaemic strokes, myocardial infarctions and DVT were the most common events ${ }^{[3]}$.

We have not found any reports of portal vein thrombosis in EGPA. However, there was a report of a 13-year-old boy with massive hepatic, mesenteric and splenic thrombi ${ }^{[4]}$. He had no respiratory involvement and ANCA was negative, but resected small bowel showed necrotizing eosinophilic vasculitis with a platelet nadir of $11,000 / \mu l$. Another case worth mentioning was that of a 48 -year-old man with acute ascites. Both ascitic fluid and peripheral blood had prominent eosinophilia. Contrast $\mathrm{CT}$ revealed portal vein and superior mesenteric vein

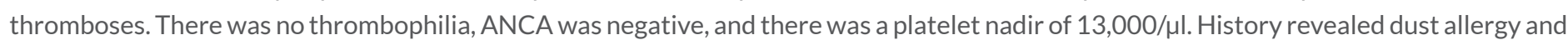
bronchodilator use ${ }^{[5]}$. The patient was diagnosed with eosinophilic vasculitis, but had insufficient criteria for EGPA.

The hypercoagulable state in EGPA is thought to occur via three pathways:

(1) activation of eosinophils,

(2) activation of the pro-thrombotic pathway, and

(3) release of endothelial factor.

The first induces the release of platelet-activating factor. This in turn induces leukocyte, endothelial and platelet activation, and releases tissue factor ${ }^{[6]}$. The second occurs ${ }^{[7]}$ via release of eosinophil peroxidase and eosinophil granule major basic protein from activated eosinophils. This, combined with a decrease in the fibrinolytic products of factor XII, induces thrombosis ${ }^{[8]}$. Furthermore, tissue factor activates factors VII and X, promoting thrombosis. The third pathway involves up-regulation of adhesion molecules by eosinophils through platelet-activating factor, platelet factor 4 and TNFa ${ }^{[9]}$. Additionally, inflammation raises levels of fibrinogen and platelets, contributing to hypercoagulability ${ }^{[10,11]}$. There are reports of severe thromboembolic events involving the portal vein in cases of transient eosinophilia ${ }^{[12-14]}$, so eosinophilia itself is a risk factor for thromboembolism ${ }^{[15]}$.

Despiteour patient'suncharacteristic presentation, we had confidence in our diagnosis duetothe tissuefindings. Thrombocytopenia, however, was extraneous. Furthermore, our patient had a negative thrombophilia work-up, including bone marrow biopsy. Abdominal discomfort and deranged liver enzymes prompted sonography, which led to the astonishing finding of portal vein thrombosis. Thrombocytopenia resolved after initiation of anticoagulation therapy, confirming that consumption was its cause.

In summary, we present a rare disease, with an extraordinary presentation that initially appeared paradoxical: a patient with EGPA, with portal vein thrombosis and thrombocytopenia. This case highlights the risk of hypercoagulability in EGPA and in eosinophilia. We suggest that eosinophilia should arouse suspicion for VTE. Portal or hepatic thrombosis should be considered. In our case, prompt diagnosis could have prevented bone marrow biopsy and hastened appropriate treatment.

On follow-up, azathioprine was prescribed, but AST and ALT rose again. Treatment was changed to methotrexate $15 \mathrm{mg}$ once a week, with good response. The patient received LMWH for 6 months. Her platelet count remained normal. Six months after discharge, she decided to stop methotrexate. A year later, all skin lesions have healed, and she remains symptom-free, without elevation of inflammatory markers, and with a normal eosinophil count. 


\section{REFERENCES}

1. Masi AT, Hunder GG, Lie JT, et al. The American College of Rheumatology 1990 criteria for the classification of Churg-Strauss syndrome (allergic granulomatosis and angiitis). Arthritis Rheum 1990;33:1094-1100.

2. Allenbach Y, Seror R, Pagnoux C, Teixeira L, Guilpain P, Guillevin L. High frequency of venous thromboembolic events in Churg-Strauss syndrome, Wegener's granulomatosis and microscopic polyangiitis but not polyarteritis nodosa: a systematic retrospective study on 1130 patients. Ann Rheum Dis 2009;68:564-567.

3. Ames PR, Margaglione M, Mackie S, Alves JD. Eosinophilia and thrombophilia in Churg Strauss syndrome: a clinical and pathogenetic overview. Clin Appl Thromb Hemost 2010;16:628-636.

4. Abdulwahab A, Almoallim H, Khan N. Isolated eosinophilic mesenteric vasculitis with extensive thrombosis and splenic infarction in a 13-year-old boy. Clin Rheumatol 2007;26:254-257.

5. Natarajan V, Jose D, John K, Das AK. Portal venous thrombosis: eosinophilic vasculitis. J Clin Diagn Res 2017;11:OD04-OD05.

6. Moosbauer C, Morgenstern E, Cuvelier SL, et al. Eosinophils are a major intravascular location for tissue factor storage and exposure. Blood $2007 ; 109: 995-1002$.

7. Slungaard A, Vercellotti GM, Tran T, Gleich GJ, Key NS. Eosinophil cationic granule proteins impair thrombomodulin function. A potential mechanism for thromboembolism in hypereosinophilic heart disease. J Clin Invest 1993;91:1721-1730.

8. Girolami A, Randi ML, Gavasso S, Lombardi AM, Spiezia F. The occasional venous thromboses seen in patients with severe (homozygous) FXII deficiency are probably due to associated risk factors: a study of prevalence in 21 patients and review of the literature. J Thromb Thrombolysis 2004;17:139-143.

9. Molet S, Gosset P, Vanhee D, et al. Modulation of cell adhesion molecules on human endothelial cells by eosinophil-derived mediators. J Leukoc Biol 1998;63:351-358.

10. Slungaard A, Vercellotti GM, Walker G, Nelson RD, Jacob HS. Tumor necrosis factor alpha/cachectin stimulates eosinophil oxidant production and toxicity towards human endothelium. J Exp Med 1990;171:2025-2041.

11. Ames PR, Roes L, Lupoli S, et al. Thrombosis in Churg-Strauss syndrome. Beyond vasculitis? Br J Rheumatol 1996;35:1181-1183.

12. Monterrubio Villar J, Cordoba Lopez A, Macayo Sanchez AJ. Idiopathic eosinophilia associated with portal vein and massive thrombosis: successful thrombolysis with streptokinase. Med Sci Monit 2006;12:Cs53-Cs56.

13. Kanno H, Ouchi N, Sato M, Wada T, Sawai T. Hypereosinophilia with systemic thrombophlebitis. Hum Pathol 2005;36:585-589.

14. Ames PR. Recurrent abdominal thrombosis despite heparin thromboprophylaxis in a patient with transient eosinophilia. Clin Appl Thromb Hemost 2011;17:229-231.

15. Lippi G, Montagnana M, Salvagno GL, Franchini M, Targher G, Guidi GC. Eosinophilia and first-line coagulation testing. J Thromb Thrombolysis 2009;28:90-93. 